\title{
SHEAR CAPACITY OF REINFORCED CONCRETE T-BEAMS RETROFIT WITH EXTERNALLY BONDED CFRP FABRIC: A NEW PERSPECTIVE
}

\author{
Robert M. Foster ${ }^{1}$, Chris T. Morley ${ }^{2}$ and Janet M. Lees ${ }^{3}$
}

\begin{abstract}
Unanchored U-wrapped externally bonded carbon fibre reinforced polymer (CFRP) fabrics are widely used to increase the design shear strength of existing reinforced concrete slab-on-beam structures, but current design models do not accurately predict the degree of enhancement. Experimental investigations further indicate that some T-beams retrofit with externally bonded CFRP fabric fail at lower shear loads than nominally identical un-retrofit reference counterparts, suggesting a negative experimental CFRP 'contribution'. This paper finds a new application for the upper-bound theorem of plasticity in analysing the problem of U-wrapped externally bonded CFRP retrofit beam behaviour. The study provides insight into the poor historical prediction of the CFRP contribution and demonstrates the limitations of a widely used experimental approach to determining this contribution. The analysis suggests a new way of thinking about the behaviour of slab-on-beam structures retrofit with unanchored U-wrapped externally bonded CFRP. The upper-bound plastic analysis provides better predictions of retrofit shear capacity than some widely used design models, indicating that this approach can lead to better design of retrofit interventions in future. A new design limit on enhancement is proposed that can reduce the likelihood of unsafe design in practice.
\end{abstract}

\section{INTRODUCTION}

Extending an existing structure's useful life is often preferable to wholesale demolition and replacement. Where the useful life of a structure is limited by design strength, retrofit interventions to enhance capacity may be appropriate. A range of retrofit techniques using bonded fibre reinforced polymers (FRPs) have been used over the past 20 years to increase the design strength of existing reinforced concrete structures (Bakis et al 2002). Among these retrofit techniques, carbon fibre reinforced polymer (CFRP) fabric externally bonded in an unanchored U-wrapped

\footnotetext{
${ }^{1}$ Lecturer in Civil Engineering, Department of Engineering, University of Cambridge, UK. http://orcid.org/00000002-6640-1793. Corresponding author, email: rmf41.cam.ac.uk

${ }^{2}$ Former Senior Lecturer in Concrete Structures, Department of Engineering, University of Cambridge, UK.

${ }^{3}$ Professor of Civil Engineering, Department of Engineering, University of Cambridge, UK.
} 
configuration offers a non-invasive and convenient method for increasing the design shear strength of reinforced concrete slab-on-beam structures. The technique is relatively well established and design guidance exists in a number of jurisdictions. Existing design guidance typically models the shear resistance of a retrofit beam as a lower-bound plastic truss limited by the minimum of the capacity of the concrete struts formed in the web, and the capacity of the ties provided by the externally bonded FRP and any internal transverse steel reinforcement e.g. fib bulletin 14 (fib 2001), HB 305-2008 (Standards Australia 2008), TR55 (Concrete Society 2012), CNR-DT 200 R1/2013 (CNR 2014). US code ACI 440.2R-17 (ACI 2017) adopts a similar approach but includes an additional empirically determined concrete contribution. Experimental studies have been carried out using realistically sized T-beam specimens retrofit with externally bonded U-wrapped unidirectional CFRP fabric in continuous sheets or discrete strips (Deniaud and Cheng 2001, Bousselham and Chaallal 2006, Altin et al 2010, Gamino et al 2010, Dias and Barros 2010, Mofidi and Chaallal 2011, Dirar et al. 2012, Belarbi et al. 2012, Ozden et al 2014, Mofidi and Chaallal 2014b, Qin et al 2015, Foster et al. 2017a, Benzeguir et al. 2018, Oller et al. 2019); providing a sizable, though far from comprehensive, empirical benchmark against which to evaluate existing guidance.

Despite considerable research effort and widespread use of this strengthening approach in practice, questions about the accuracy (Lima and Barros 2011, Chen and Cheng 2019) and appropriateness (Petrone and Monti 2014) of the models underpinning existing guidance have been raised. In particular, the assumption underlying most current guidance - that the concrete, steel and FRP contributions to resistance are independent - is drawn into question by experimental studies (Bousselham et al. 2006, Belarbi et al. 2012, Mofidi et al. 2014). An apparent reduction in the enhancement available from the externally bonded FRP associated with increasing transverse reinforcement provision as a result of premature separation of the FRP material from the concrete substrate has been termed an "adverse shear interaction" (Chen et al. 2013, Chen et al. 2017). Models have addressed this interaction using modification factors considering the ratios of steel and FRP reinforcements (Mofidi and Chaallal 2011) or through mechanical models enforcing weak (Pellegrino and Modena 2008) or strong (Petrone and Monti 2014) compatibility conditions on the steel and FRP strains. The role of bond between the concrete substrate and the CFRP in relation to the effective capacity of the externally bonded system has been extensively investigated (Khalifa et al. 1998, Triantafillou and Antonopoulos 2000, Denton et al. 2004, Mofidi and Challal 2011, Chen et al. 2013, Chen et al. 2017).

In order to mitigate limitations associated with deficient bond, investigators have shown that the provision of full wrapping of T-beams with straps (Hoult and Lees 2009) or the provision of various forms of enhanced anchorage near the flange soffit (Mofidi et al. 2012, Foster et al. 2017a, Oller et al. 2019) can result in considerably greater shear enhancement than has been associated with unanchored externally bonded U-wrapped fabric. Similarly, near-surface mounted bars (De Lorenzis and Nanni 2001, Mofidi and Chaallal 2016) and deep-embedded bars (Valerio et al 2009) have been shown to have the potential to gain attain greater shear enhancement than externally- 
bonded fabrics. Notwithstanding this, externally bonded fabrics without additional anchorage continue to be used in practice.

\section{BASIS FOR INVESTIGATION}

\section{Poor predictability of FRP 'contribution'}

As Bentz et al. (2006) note, shear strength predictions for reinforced concrete beams may differ between design codes by a factor of two, while flexural strength predictions seldom vary by more than ten percent. It is therefore unsurprising that predictions of the shear capacity of a reinforced concrete beam retrofit with externally bonded CFRP can also vary widely. Lima and Barros' (2011) analysis of a database of more than 250 FRP-strengthened beam tests shows that, for a range of externally bonded retrofit FRP configurations, none of the design models considered were able to accurately predict the FRP 'contribution'. In order to understand this historic inability to accurately predict the FRP contribution to shear resistance, it is necessary to consider the way in which this contribution is determined experimentally. As noted by Petrone and Monti (2014), most research efforts have concentrated on accurately determining an FRP contribution, rather than describing a comprehensive mechanical model for retrofit beam behaviour. This has led to an experimental approach that focuses on identifying a distinct component of shear resistance $V_{\text {frp }}$ that represents

the FRP 'contribution'. The value of $V_{\text {frp }}$ is determined by subtracting the resistance of a single reference beam from that of a notionally identical counterpart beam that has been retrofit with FRP. This means that model predictions are verified, not against the actual enhancement to a particular beam, but rather against the difference between beam shear tests on two different reinforced concrete beams; one with and one without externally bonded FRP retrofit. Variability in both the reference and the retrofit beam tests thus influence the value of $V_{\text {frp }}$ inferred. With few exceptions (e.g., Gamino et al. 2010, Foster et al. 2017a, Oller et al. 2019) CFRP retrofit studies report the testing of only a single reference beam for each arrangement, meaning that information as to the variability of the reference beams is generally unavailable. Unacknowledged variability in reference specimens may thus be at least a partial explanation for the historically poor prediction of experimentally determined $V_{f p}$.

\section{Negative CFRP 'contribution'}

In addition to the poor predictability of the FRP contribution, some investigators (Deniaud and Cheng 2001, Bousselham and Chaallal 2006, Foster et al 2017a, Benzeguir et al. 2018, Oller et al. 2019) report tests in which realistically sized reinforced concrete T-beams retrofit with externally bonded CFRP demonstrate lower shear capacities than some reference counterparts [Table 1]. Following the logic of the subtractive experimental method, this suggests a negative 'contribution' associated with the CFRP retrofit intervention. Such results would appear to contradict the theoretical underpinnings of much design practice and thus their proper consideration should be of high interest. Despite this, due significance has not been attributed to these experimental results 
and they have been little discussed in the wider literature. This may be at least partly due to skewed reporting of some results whereby positive differences between results of retrofit and reference tests are tabulated as positive gain, while negative differences between results are reported as zero gain (e.g., Bousselham and Chaallal 2006, Benzeguir et al. 2018).

Oller et al (2019) observe that the compressive strut inclination may be modified by the presence of the retrofit, affecting the transverse steel reinforcement contribution and possibly explaining the lower failure loads observed in some retrofit beams relative to their reference counterparts. This is compatible with the observation by Foster at al. (2017a) that variability in critical diagonal crack angle might explain variability in capacity; and that the more consistent, intermediate crack inclinations observed in the retrofit beams might explain the intermediate capacities achieved by these retrofit beams (i.e. capacities falling between those of the stronger and weaker of the reference beams).

Table 1: Instances of apparently negative EB CFRP contribution

\begin{tabular}{|c|c|c|c|c|c|c|}
\hline \multirow{3}{*}{$\begin{array}{l}\text { Original } \\
\text { investigators }\end{array}$} & \multicolumn{2}{|c|}{ Reference T-beam } & \multicolumn{2}{|c|}{ Retrofit T-beam } & \multirow{3}{*}{$\begin{array}{c}\text { Apparent } \\
\text { 'gain' due } \\
\text { to retrofit } \\
\%\end{array}$} & \multirow{3}{*}{$\begin{array}{l}\text { Original investigators } \\
\text { observations on negative } \\
\text { 'gain' }\end{array}$} \\
\hline & Designation & $V_{\mathrm{o}}$ & Designation & $V_{\mathrm{o}}$ & & \\
\hline & & $\mathbf{k N}$ & & $\mathbf{k N}$ & & \\
\hline $\begin{array}{l}\text { Deniaud and } \\
\text { Cheng } 2001\end{array}$ & T6S2 & 357 & T6S2C90 & 310 & -13 & $\begin{array}{l}\text { Result attributed to } \\
\text { unspecified variability in the } \\
\text { experimental specimens; } \\
\text { possible sliding failure along } \\
\text { critical crack }\end{array}$ \\
\hline $\begin{array}{l}\text { Bousselham and } \\
\text { Chaallal } 2006\end{array}$ & SB-S1-0L & 263 & SB-S1-1L & 255 & -5 & Result not commented upon \\
\hline \multirow{6}{*}{ Foster et al 2017a } & \multirow{2}{*}{$\mathrm{LBC}$} & \multirow{2}{*}{472} & LB0.7U & 458 & -3 & \multirow{6}{*}{$\begin{array}{l}\text { Result attributed to } \\
\text { variability in the critical } \\
\text { crack angle formation in } \\
\text { reference beams; } \\
\text { modification of the critical } \\
\text { crack angle due to the } \\
\text { presence of retrofit; and } \\
\text { separation of CFRP leading } \\
\text { to web cover concrete loss } \\
\text { in the vicinity of the critical } \\
\text { diagonal crack }\end{array}$} \\
\hline & & & LB1.3U & 437 & -7 & \\
\hline & & & MC0.9U & 299 & -7 & \\
\hline & & & $\mathrm{MC} 1.3 \mathrm{U}$ & 306 & -5 & \\
\hline & \multirow{2}{*}{$\mathrm{SCC}_{1}$} & \multirow{2}{*}{195} & SC0.7U & 166 & -15 & \\
\hline & & & SC1.3U & 153 & -22 & \\
\hline \multirow{2}{*}{$\begin{array}{l}\text { Benzeguir et al } \\
2018\end{array}$} & MS1Con & 268 & MS1EBS & 260 & -3 & \multirow{2}{*}{ Result not commented upon } \\
\hline & LS1Con & 600 & LS1EBS & 590 & -2 & \\
\hline \multirow[b]{2}{*}{ Oller et al 2019} & M0a & 300 & M2a & 285 & -5 & \multirow{2}{*}{$\begin{array}{l}\text { Result attributed to the } \\
\text { presence of retrofit } \\
\text { modifying the strut } \\
\text { inclination/critical crack } \\
\text { angle leading to lower failure }\end{array}$} \\
\hline & $\mathrm{M} 0 \mathrm{~b}$ & 310 & M2b & 259 & -16 & \\
\hline
\end{tabular}




\section{PLASTIC WEB-CRUSHING ANALYSIS}

The variability of reference specimens and the failure of some retrofit beams at lower loads than their reference counterparts raise the question as to what reference value 'should' be used for the purposes of investigating the influence of the CFRP retrofit. One way of approaching this problem is to consider an upper bound on the capacity expected from the reference beam. While the lower bound theorem of plasticity is widely used in the design of reinforced concrete, it has been noted that it may be advantageous to use the upper bound theory for the purposes of assessment, provided suitable values for the effectiveness of the concrete are included in the analysis (Ibell et al. 1997, Foster et al. 2017b). This paper applies an upper-bound plastic web-crushing analysis to reinforced concrete T-beams retrofit with externally bonded CFRP and their reference counterparts, in order to investigate the influence of the CFRP retrofit on beam capacity.

\section{Assumptions}

An upper bound plastic analysis considers the work done by displacement of external loads and the energy dissipated by yielding of material for a compatible failure mechanism. Upper and lower bound solutions for the shear strength of reinforced concrete beams with and without transverse reinforcement were presented by Nielsen, Braestrup, Jensen and others in the 1970s and 1980s (Jensen 1977, Nielsen et al 1978, Nielsen and Hoang 2011).

The following assumptions are usually made in applying the upper bound theory of plasticity to the behaviour of reinforced concrete:

1. Perfectly plastic material behaviour is assumed such that strains prior to yielding of the material are negligible, and strains thereafter may be arbitrarily large.

2. An effectiveness factor $v$ for concrete in compression is applied such that the effective concrete strength in compression is $v f_{c}$, where $f_{c}$ is the uniaxial concrete compressive cylinder strength. The effectiveness $v$ is intended to account for a number of effects including softening, micro-cracking and local stress concentrations (Nielsen \& Hoang 2011).

3. A Modified-Coulomb failure criterion for concrete is adopted. The concrete is treated as a granular material with a friction angle $\varphi$ of $37^{\circ}$ under all combinations of stress (Nielsen \& Hoang 2011). A limiting concrete tensile strength $f_{t}=0$ is assumed here.

4. Steel reinforcing bars are assumed to carry only axial forces and yield at stress $f_{y}$. Dowel action of reinforcement is not explicitly considered in the analysis although its influence 
will be somewhat implicit in any values of effectiveness factors inferred from experimental results.

A web-crushing mechanism is considered in this analysis. The minimum value of shear capacity obtained for the plastic web-crushing mechanism is taken as the predicted capacity $V_{p}$. Further assumptions are made here for the case of a web-crushing analysis for reinforced concrete $\mathrm{T}$ beams:

5. The internal transverse steel reinforcement ratio is constant along the shear span, i.e., the reinforcement is sufficiently closely spaced that bar forces can be replaced by an equivalent transverse reinforcement stress $\varrho_{s v} f_{y v}$. The parameter $\varrho_{s v}$ is the transverse steel reinforcement ratio defined as:

$$
\rho_{s v}=\frac{A_{s v}}{s_{s v} b_{w}}
$$

where $A_{s v}$ is the cross-sectional area of the internal transverse steel, $s_{s v}$ is the spacing of the internal transverse steel, $b_{w}$ is the breadth of the web and $f_{y v}$ is the transverse steel yield stress.

6. The compression and tension chords are assumed sufficiently strong to ensure that the relative displacement rate $u$ is vertical. If a beam is not already failing in flexure, it follows from the assumption of perfectly plastic material behaviour that any unyielding longitudinal reinforcement prevents horizontal displacement. This assumption is likely to be appropriate for the T-beam specimens typically designed for experimental investigations, which have a substantial flange and relatively high longitudinal steel ratios in order to prevent flexural failure. However, in practice, combined flexural-shear failure modes may occur and it should be understood that these are not described by the singledegree-of-freedom kinematic posited here.

7. Only the beam web section is considered in the analysis; any contribution from the flange is neglected.

No material properties, bond characteristics or reinforcement parameters are described for the retrofit CFRP. This study does not assume ductile behaviour of the CFRP or the CFRP-concrete interface meaning that the CFRP is not included in this upper-bound plastic model. The reference and retrofit beams are subject to exactly the same analysis, based solely on the properties of the underlying reinforced concrete beam. By considering only the properties of the underlying beam, the effect of the presence of the CFRP on the behaviour of the underlying beam is investigated.

\section{Model}

The T-beam profile is treated as a rectangular effective section of breadth $b_{\mathrm{w}}$ and depth $\%$ where $z$ is the flexural lever arm and is taken as 0.9 of the effective tensile reinforcement depth $d$. The 
nominal shear stress $\tau$ and non-dimensional transverse steel reinforcement parameter $\psi$ are defined as:

$$
\begin{gathered}
\tau=\frac{V}{b_{w} z} \\
\psi=\frac{\rho_{s v} f_{y v}}{f_{c}}
\end{gathered}
$$

A straight yield line on $\mathrm{AB}$ at variable angle $\beta$ to the longitudinal axis is assumed as shown in Figure 1a. The thickness of this yield line is arbitrary, so the alternative mechanism with a trapezoidal region of uniform strain shown in Figure 1c, which better resembles the observed deformations of some beams, remains equivalent to that shown in Figure 1b. For a purely vertical relative displacement $u$ of the rigid bodies 1 and 2 , the following equations thus constitute a coinciding upper and lower bound solution (Nielsen and Hoang 2011) for different values of $\tan \beta$ :

$$
\begin{array}{cl}
\frac{\tau}{v f_{c}}=0.5\left[\sqrt{1+\left(\frac{L}{z}\right)^{2}}-\frac{L}{Z}\right]+\frac{\psi}{v} \frac{L}{z} & \text { for: } \tan \beta<\frac{z}{L} \\
\frac{\tau}{v f_{c}}=\sqrt{\frac{\psi}{v}\left(1-\frac{\psi}{v}\right)} & \text { for: } \frac{z}{L} \leq \tan \beta \leq \infty \\
\psi \geq 0.5, \quad \frac{\tau}{v f_{c}}=0.5 & \text { for: } \tan \beta=\infty
\end{array}
$$

where $\beta$ is:

$$
\tan \beta=\frac{2 \sqrt{\frac{\psi}{v}\left(1-\frac{\psi}{v}\right)}}{1-2\left(\frac{\psi}{v}\right)}
$$

The inclination $\beta$ of the yield line can also be shown to be equal to $2 \theta$, the inclination of the diagonal compression field in the corresponding lower bound solution (Nielsen and Hoang 2011). The closed form of the equations allow for direct solution. Equation (5) governs in most cases.

An effectiveness factor is introduced in order to reconcile the theoretical assumption of perfect plasticity with the empirical reality. Since the actual effectiveness factor is unknown, an estimate must be made. A general-purpose single-parameter effectiveness factor for normal strength concrete of 


$$
v=0.6\left(1-\frac{f_{c}}{250}\right)
$$

was adopted for this analysis, in accordance with the suggestion of Eurocode 2 (BSI 2004). In equation (6) $f_{c}$ is expressed in $\mathrm{MPa}$ and the resulting effectiveness factor is treated as a unit-less coefficient.

(a)
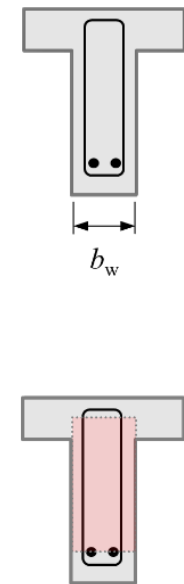

(c)



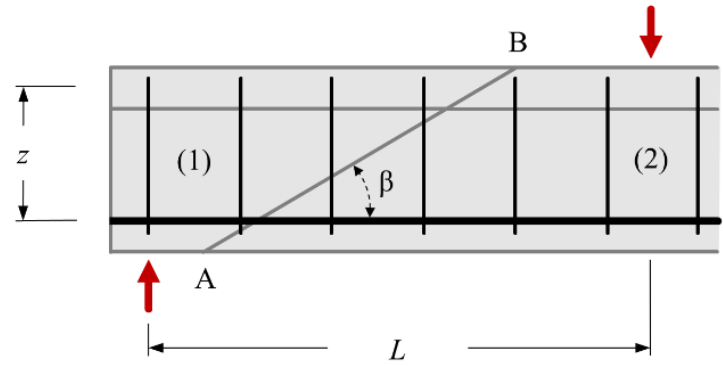
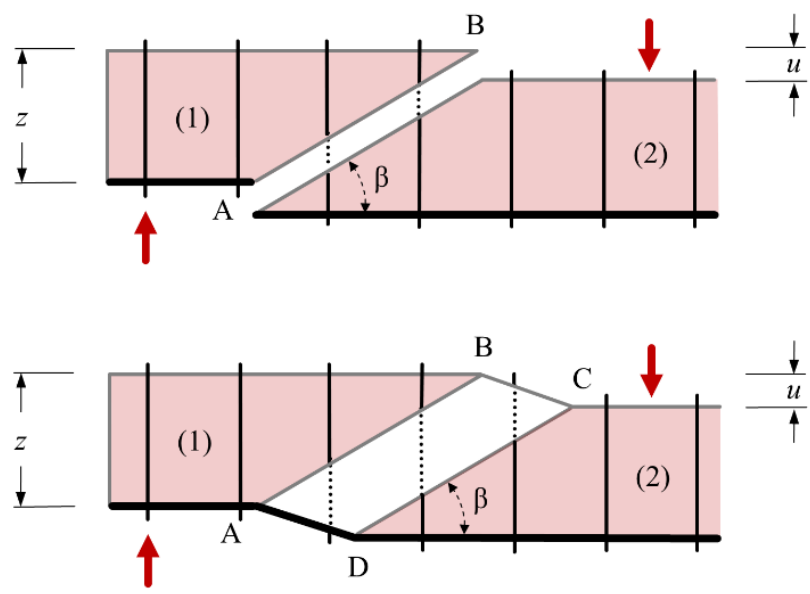

Figure 1. Web-crushing failure kinematic

Alternative models adapt the upper-bound plastic approach to account for the possibility of 'sliding' failure along macro-cracks (Zhang 1994, Nielsen and Hoang 2011). These macro-cracks are modelled as yield lines of reduced strength through the incorporation of a further effectiveness factor $\boldsymbol{v}_{s}$ which is typically assigned a value of 0.5 (Zhang 1997). It has been noted that so-called 'crack-sliding' failures are likely to precede web-crushing in beams with levels of transverse steel reinforcement $\psi$ less than approximately 0.05v (Nielsen \& Hoang 2011). Crack-sliding models typically determine the capacity associated with a critical diagonal crack location within the span, determined with reference to the flexural stresses that produce tension failure in the concrete. In reality, the formation and propagation of macro-cracks may be a function of further unknown parameters such as residual stresses, thermal stresses, imperfections and voids - in addition to the flexural stresses due to the applied load - meaning that there is considerable uncertainty as to the cracking behaviour of any particular beam. While a crack-sliding analysis is not presented as part of this investigation, the observation that beams with low levels of transverse steel reinforcement 
may be prone to a crack-sliding failure that prevents them from attaining the capacity predicted by the web-crushing analysis is helpful in interpreting the results of this investigation.

\section{Dataset selected for analysis}

A large number of experimental investigations are reported in the literature addressing a range of FRP retrofit configurations, beam geometries, reinforcement configurations and material properties. However, the wide range of parameters investigated means that the number of tests pertaining to any particular combination is limited. As a result, some combinations that are widely encountered in practice are not well represented in the literature. The present investigation is concerned with the behaviour of slab-on-beam structures retrofit in shear with unanchored externally bonded U-wrapped CFRP fabrics. Tests on T-shaped beams are chosen here as an appropriate experimental proxy for a slab-on-beam arrangement.

Lima and Barros' (2011) survey of over 250 beams retrofit in shear with externally bonded FRP found that less than $20 \%$ of tested beams were T-shaped. Reflecting upon the nature and quality of the available data, Lima and Barros (2011) highlight the need to carry out analyses on suitable subsets of the available data in order to reduce the influence of error and inconsistency. A recent dataset collected by Ji et al (2017) targets beams retrofit with externally bonded U-wrapped CFRP only. The dataset reports 256 beam tests, including 48 tests on slender T-beams with transverse reinforcement. Beam tests for which the retrofit beam displayed lower resistance than the reference beam were excluded from the Ji et al (2017) dataset on the basis that they represent an "abnormal shear contribution of the FRP". This means that tests resulting in negative values of $V_{f p}$, such as those listed in Table 1, were not considered. Sixteen beam test entries in the Ji et al (2017) database appear to be republications of previously presented results with new beam designations, rather than new tests.

A database of T-beam tests was compiled for this study. The following qualitative criteria were applied:

1. Retrofit beam test results were not censored to exclude 'negative' results.

2. Apparent republications of results were excluded. Where exceptionally similar results are reported for separately published tests that have at least one common investigator, only the apparent first reporting is included in the database. Six such beams were excluded on this basis: beams WT-ST-50, W'T-ST-70 and WT-SH-100 (Mofidi and Chaallal 2014b); and HR-ST-LF, HR-ST-HF and HR-SH (Mofidi and Chaallal 2014a); as these appear to be republications of S1-0.17R2, S1-0.23R and S1-0.33R (Mofidi and Chaallal 2011).

The following quantitative criteria were also applied:

3. Transverse reinforcement, $\varrho_{\text {sv }}>0$

4. Effective depth, $d \geq 200 \mathrm{~mm}$

5. Slenderness, $L / d \geq 2.5$ 
These criteria ensure that experimental results selected were 'realistic' in size and somewhat representative of typical slender slab-on-beam structures. The database was further limited to CFRP retrofit systems that were:

6. Applied to an initially unloaded T-beam;

7. Unidirectional, with principal fibre orientation perpendicular to the longitudinal axis of the beam;

8. Externally bonded and arranged in continuous sheets or discrete strips;

9. Without additional mechanical anchorage.

T-beams retrofit in the shear span without additional anchorage and with unidirectional fibres perpendicular to the longitudinal axis of the beam is an arrangement that is permitted by most design guidance and commonly encountered in practice.

These criteria led to a dataset of 38 retrofit T-beam tests and a further 25 reference T-beams pertaining to these same tests (Deniaud and Cheng 2001, Bousselham and Chaallal 2006, Altin et al 2010, Gamino et al 2010, Dias and Barros 2010, Mofidi and Challaal 2011, Belarbi et al. 2012, Ozden et al 2014, Mofidi and Chaallal 2014b, Qin et al 2015, Foster et al. 2017a, Benzeguir et al. 2018, Oller et al. 2019). Only three of the studies identified (Gamino et al 2010, Foster et al 2017a, Oller et al. 2019) included the testing of multiple reference beams for a given set of parameters. The dataset of beams and relevant properties are listed in Table 2.

The dataset captures a total of 63 beams with variation in a wide range of parameters including: effective depth $d$ from $265 \mathrm{~mm}$ to $831 \mathrm{~mm}$; transverse steel ratios $\varrho_{s v} f_{y v}$ from 0.31 to $2.46 \mathrm{MPa}$; shear span to effective depth ratios $L / d$ from 2.5 to 5.0; transverse FRP ratios $\varrho_{f p p} E_{f p p}$ from 81 to $1533 \mathrm{MPa}$; concrete strengths $f_{c}$ from 12.4 to $60 \mathrm{MPa}$; and longitudinal reinforcement ratios $\varrho_{s l}$ from 1.6 to $5.9 \%$. Where the value of $f_{c}$ for each individual beam is reported by the original investigators, these values are used. Otherwise, mean values of $f_{c}$ reported for that series are used. Values of $\varrho_{s l}$ reported in all of these investigations are relatively high in order to ensure shear failure rather than flexural failure during testing. High values of $\varrho_{s l}$ are not necessarily unrealistic, as beams that are identified as candidates for shear strengthening must be those that have a sufficient margin of additional flexural capacity in order to ensure a ductile failure mode. 
Table 2: Beam data

\begin{tabular}{|c|c|c|c|c|c|c|c|c|c|c|c|c|c|c|c|c|c|c|c|}
\hline \multirow{2}{*}{ Investigator } & \multicolumn{2}{|c|}{ Beam designation } & \multirow{2}{*}{$\begin{array}{c}f_{c}{ }^{1} \\
\mathrm{MPa} \\
\end{array}$} & \multirow{2}{*}{$\begin{array}{c}b_{W} \\
\mathrm{~mm}\end{array}$} & \multirow{2}{*}{$\begin{array}{c}d \\
\mathrm{~mm}\end{array}$} & \multirow[t]{2}{*}{$L / d$} & \multirow{2}{*}{$\begin{array}{l}\varrho_{s v} f_{y V} \\
\mathrm{MPa}\end{array}$} & \multirow{2}{*}{$\begin{array}{c}\varrho_{f p} E_{f f p} \\
\mathbf{M P a}\end{array}$} & \multirow[t]{2}{*}{$\begin{array}{c}W_{\mathrm{f}} / \\
s_{\mathrm{f}}\end{array}$} & \multirow{2}{*}{$\begin{array}{l}\varrho_{s l} \\
\%\end{array}$} & \multirow{2}{*}{$\begin{array}{c}\psi / v \\
\% 0\end{array}$} & \multirow{2}{*}{$\begin{array}{r}V_{\mathrm{u}} \\
\mathrm{kN} \\
\end{array}$} & \multirow{2}{*}{$\begin{array}{r}V_{\mathrm{p}} \\
\mathrm{kN} \\
\end{array}$} & \multirow{2}{*}{$\begin{array}{l}V_{\mathrm{tr} 55} \\
\mathrm{kN}\end{array}$} & \multirow{2}{*}{$\begin{array}{l}V_{t+55+} \\
\mathrm{kN}\end{array}$} & \multirow{2}{*}{$\begin{array}{l}V_{\mathrm{cnr}} \\
\mathrm{kN}\end{array}$} & \multirow{2}{*}{$\begin{array}{c}V_{c n r}+ \\
\mathrm{kN}\end{array}$} & \multirow{2}{*}{$\begin{array}{l}V_{\mathrm{aci}} \\
\mathrm{kN}\end{array}$} & \multirow{2}{*}{$\begin{array}{c}V_{a c i}+ \\
\mathrm{kN}\end{array}$} \\
\hline & $\begin{array}{l}\text { Reference } \\
\text { beam }\end{array}$ & Retrofit beam & & & & & & & & & & & & & & & & & \\
\hline \multirow{12}{*}{$\begin{array}{l}\text { Oller et al } \\
2019\end{array}$} & M0a & - & 40.2 & 200 & 493 & 3.0 & 0.76 & - & 0.00 & 1.6 & 38 & 300 & 342 & 169 & 169 & 169 & 169 & 181 & 181 \\
\hline & M0b & - & 40.2 & 200 & 493 & 3.0 & 0.76 & - & 0.00 & 1.6 & 38 & 310 & 342 & 169 & 169 & 169 & 169 & 181 & 181 \\
\hline & - & M1a & 42.8 & 200 & 493 & 3.0 & 0.76 & 81 & 0.21 & 1.6 & 36 & 349 & 351 & - & - & - & - & 207 & 207 \\
\hline & - & M1b & 42.8 & 200 & 493 & 3.0 & 0.76 & 81 & 0.21 & 1.6 & 36 & 325 & 351 & - & - & - & - & 207 & 207 \\
\hline & - & $\mathrm{M} 2 \mathrm{a}$ & 39.8 & 200 & 493 & 3.0 & 0.76 & 163 & 0.42 & 1.6 & 38 & 285 & 340 & - & - & 331 & 331 & 225 & 225 \\
\hline & - & M2b & 39.8 & 200 & 493 & 3.0 & 0.76 & 163 & 0.42 & 1.6 & 38 & 259 & 340 & - & - & 330 & 330 & 225 & 225 \\
\hline & $\mathrm{HOa}$ & - & 42.6 & 200 & 493 & 3.0 & 0.76 & - & 0.00 & 5.9 & 36 & 327 & 350 & 169 & 169 & 169 & 169 & 184 & 184 \\
\hline & $\mathrm{H} 0 \mathrm{~b}$ & - & 42.6 & 200 & 493 & 3.0 & 0.76 & - & 0.00 & 5.9 & 36 & 320 & 350 & 169 & 169 & 169 & 169 & 184 & 184 \\
\hline & - & $\mathrm{H} 1 \mathrm{a}$ & 44.4 & 200 & 493 & 3.0 & 0.76 & 81 & 0.21 & 5.9 & 35 & 334 & 356 & - & - & - & - & 209 & 209 \\
\hline & - & $\mathrm{H} 1 \mathrm{~b}$ & 44.4 & 200 & 493 & 3.0 & 0.76 & 81 & 0.21 & 5.9 & 35 & 336 & 356 & - & - & - & - & 209 & 209 \\
\hline & - & $\mathrm{H} 2 \mathrm{a}$ & 49.7 & 200 & 493 & 3.0 & 0.76 & 163 & 0.42 & 5.9 & 32 & 338 & 372 & - & - & 343 & 343 & 238 & 238 \\
\hline & - & $\mathrm{H} 2 \mathrm{~b}$ & 49.7 & 200 & 493 & 3.0 & 0.76 & 163 & 0.42 & 5.9 & 32 & 340 & 372 & - & - & 342 & 342 & 238 & 238 \\
\hline \multirow{4}{*}{$\begin{array}{l}\text { Benzeguir et } \\
\text { al } 2018\end{array}$} & M.S1.Con & - & 30.0 & 152 & 350 & 3.0 & 0.38 & - & 0.00 & 3.7 & 155 & 268 & 275 & 262 & 262 & 262 & 262 & 179 & 179 \\
\hline & - & M.S1.EBS & 30.0 & 152 & 350 & 3.0 & 0.38 & 329 & 1.00 & 3.7 & 155 & 260 & 275 & 293 & 275 & 331 & 275 & 229 & 229 \\
\hline & L.S1.Con & - & 30.0 & 275 & 525 & 3.0 & 0.32 & - & 0.00 & 3.6 & 90 & 600 & 588 & 462 & 462 & 462 & 462 & 337 & 337 \\
\hline & - & L.S1.EBS & 30.0 & 275 & 525 & 3.0 & 0.32 & 284 & 1.00 & 3.6 & 90 & 590 & 588 & 571 & 571 & 755 & 588 & 452 & 452 \\
\hline & LBC & - & 44.0 & 300 & 600 & 3.5 & 0.31 & - & 0.00 & 2.2 & 14 & 472 & 420 & 127 & 127 & 127 & 127 & 255 & 255 \\
\hline & - & LB0.7U & 48.2 & 300 & 600 & 3.5 & 0.31 & 703 & 1.00 & 2.2 & 13 & 458 & 436 & 361 & 361 & 945 & 436 & 539 & 426 \\
\hline & - & LB1.3U & 49.6 & 300 & 600 & 3.5 & 0.31 & 1277 & 1.00 & 2.2 & 13 & 437 & 442 & 434 & 434 & 1212 & 442 & 636 & 442 \\
\hline & $\mathrm{MCC}_{1}$ & - & 49.1 & 225 & 450 & 3.5 & 0.53 & - & 0.00 & 2.4 & 23 & 250 & 319 & 121 & 121 & 121 & 121 & 172 & 172 \\
\hline & $\mathrm{MCC}_{2}$ & - & 47.8 & 225 & 450 & 3.5 & 0.53 & - & 0.00 & 2.4 & 23 & 225 & 316 & 121 & 121 & 121 & 121 & 170 & 170 \\
\hline & $\mathrm{MBC}$ & - & 47.1 & 225 & 450 & 3.5 & 0.41 & - & 0.00 & 2.4 & 18 & 322 & 275 & 92 & 92 & 92 & 92 & 156 & 156 \\
\hline $2017 \mathrm{a}$ & - & $\mathrm{MC} .9 \mathrm{U}$ & 49.4 & 225 & 450 & 3.5 & 0.53 & 852 & 1.00 & 2.4 & 22 & 299 & 320 & 285 & 285 & 699 & 320 & 367 & 320 \\
\hline & - & MB1.3U & 51.3 & 225 & 450 & 3.5 & 0.41 & 1320 & 1.00 & 2.4 & 17 & 306 & 284 & 278 & 278 & 773 & 284 & 408 & 284 \\
\hline & $\mathrm{SCC}_{1}$ & - & 52.3 & 150 & 300 & 3.5 & 0.43 & - & 0.00 & 3.5 & 17 & 195 & 132 & 44 & 44 & 44 & 44 & 123 & 123 \\
\hline & $\mathrm{SCC}_{2}$ & - & 47.2 & 150 & 300 & 3.5 & 0.43 & - & 0.00 & 3.5 & 19 & 89 & 127 & 44 & 44 & 44 & 44 & 71 & 71 \\
\hline & - & SC0.7U & 50.0 & 150 & 300 & 3.5 & 0.43 & 703 & 1.00 & 3.5 & 18 & 166 & 129 & 117 & 117 & 328 & 129 & 157 & 129 \\
\hline & - & SC1.3U & 50.6 & 150 & 300 & 3.5 & 0.43 & 1405 & 1.00 & 3.5 & 18 & 153 & 130 & 143 & 130 & 367 & 130 & 204 & 130 \\
\hline Qin et al 2015 & N00 & - & 21.0 & 125 & 295 & 3.1 & 1.59 & - & 0.00 & 5.3 & 137 & 143 & 132 & 132 & 132 & 132 & 132 & 87 & 87 \\
\hline & - & $\mathrm{S} 00$ & 29.6 & 125 & 295 & 3.1 & 1.59 & 1533 & 1.00 & 5.3 & 101 & 182 & 157 & 187 & 157 & 241 & 157 & 177 & 157 \\
\hline Mofidi and & $\mathrm{MR} / \mathrm{NF}$ & - & 35.0 & 152 & 350 & 3.0 & 1.64 & - & 0.00 & 3.2 & 91 & 195 & 249 & 197 & 197 & 197 & 197 & 140 & 140 \\
\hline Chaallal 2014 & - & $\mathrm{MR} / \mathrm{SH}$ & 35.0 & 152 & 350 & 3.0 & 1.64 & 333 & 1.00 & 3.2 & 91 & 222 & 249 & 243 & 243 & 336 & 249 & 190 & 190 \\
\hline Ozden et al & Control & - & 12.4 & 120 & 320 & 3.8 & 0.35 & - & 0.00 & 3.2 & 49 & 55 & 53 & 30 & 30 & 30 & 30 & 36 & 36 \\
\hline 2014 & - & FBwoA-CFRP & 12.4 & 120 & 320 & 3.8 & 0.35 & 87 & 0.17 & 3.2 & 49 & 62 & 53 & - & - & - & - & 41 & 41 \\
\hline
\end{tabular}




\begin{tabular}{|c|c|c|c|c|c|c|c|c|c|c|c|c|c|c|c|c|c|c|c|}
\hline \multirow{4}{*}{$\begin{array}{l}\text { Belarbi et al. } \\
2012\end{array}$} & RC-12-Con. & - & 19.9 & 457 & 851 & 3.2 & 0.29 & - & 0.00 & 2.8 & 26 & 681 & 863 & 541 & 541 & 541 & 541 & 518 & 518 \\
\hline & - & RC-12-S90 & 20.7 & 457 & 851 & 3.2 & 0.29 & 88 & 0.67 & 2.8 & 25 & 851 & 892 & 642 & 642 & - & - & 626 & 626 \\
\hline & RC-8-Con. & - & 19.3 & 457 & 851 & 3.2 & 0.43 & - & 0.00 & 2.8 & 40 & 551 & 721 & 361 & 361 & 361 & 361 & 441 & 441 \\
\hline & - & RC-8-S90 & 19.3 & 457 & 851 & 3.2 & 0.43 & 88 & 0.67 & 2.8 & 40 & 765 & 858 & 462 & 462 & - & - & 604 & 604 \\
\hline \multirow{5}{*}{$\begin{array}{l}\text { Mofidi and } \\
\text { Chaallal } 2011\end{array}$} & S1-0.0R & - & 31.0 & 152 & 350 & 3.0 & 2.04 & - & 0.00 & 3.7 & 125 & 232 & 258 & 244 & 244 & 244 & 244 & 158 & 158 \\
\hline & - & S1-0.17R1 & 31.0 & 152 & 350 & 3.0 & 2.04 & 167 & 0.50 & 3.7 & 125 & 242 & 258 & - & - & 297 & 258 & 183 & 183 \\
\hline & - & S1-0.17R2 & 31.0 & 152 & 350 & 3.0 & 2.04 & 167 & 0.50 & 3.7 & 125 & 247 & 258 & - & - & 297 & 258 & 183 & 183 \\
\hline & - & S1-0.23R & 31.0 & 152 & 350 & 3.0 & 2.04 & 234 & 0.70 & 3.7 & 125 & 254 & 258 & 272 & 258 & 309 & 258 & 193 & 193 \\
\hline & - & S1-0.33R & 31.0 & 152 & 350 & 3.0 & 2.04 & 333 & 1.00 & 3.7 & 125 & 251 & 258 & 278 & 258 & 326 & 258 & 208 & 208 \\
\hline \multirow{4}{*}{$\begin{array}{l}\text { Altin et al } \\
2010\end{array}$} & 1 & - & 25.0 & 120 & 330 & 5.0 & 0.43 & - & 0.00 & 2.4 & 32 & 50 & 85 & 38 & 38 & 38 & 38 & 50 & 50 \\
\hline & - & 2 & 25.2 & 120 & 330 & 5.0 & 0.43 & 185 & 0.40 & 2.4 & 32 & 83 & 85 & - & - & 110 & 85 & 71 & 71 \\
\hline & - & 3 & 24.9 & 120 & 330 & 5.0 & 0.43 & 154 & 0.33 & 2.4 & 32 & 82 & 85 & - & - & 99 & 85 & 67 & 67 \\
\hline & - & 4 & 24.8 & 120 & 330 & 5.0 & 0.43 & 116 & 0.25 & 2.4 & 32 & 69 & 84 & - & - & - & - & - & - \\
\hline \multirow{4}{*}{$\begin{array}{l}\text { Dias and } \\
\text { Barros } 2010\end{array}$} & $2 S-R$ & - & 39.7 & 180 & 360 & 2.5 & 0.57 & - & 0.00 & 2.8 & 28 & 182 & 194 & 83 & 83 & 83 & 83 & 105 & 105 \\
\hline & - & $2 \mathrm{~S}-4 \mathrm{M}$ & 39.7 & 180 & 360 & 2.5 & 0.57 & 142 & 0.33 & 2.8 & 28 & 187 & 194 & - & - & 178 & 178 & 131 & 131 \\
\hline & - & 2S-7M(1) & 39.7 & 180 & 360 & 2.5 & 0.57 & 450 & 0.53 & 2.8 & 28 & 195 & 194 & 144 & 144 & 275 & 194 & 172 & 172 \\
\hline & - & $2 \mathrm{~S}-7 \mathrm{M}(2)$ & 39.7 & 180 & 360 & 2.5 & 0.57 & 450 & 0.53 & 2.8 & 28 & 222 & 194 & 145 & 145 & 275 & 194 & 173 & 173 \\
\hline \multirow{4}{*}{$\begin{array}{l}\text { Gamino et al } \\
2010\end{array}$} & RTC1 & - & 59.0 & 120 & 265 & 2.6 & 0.57 & - & 0.00 & 2.0 & 21 & 74 & 112 & 41 & 41 & 41 & 41 & 59 & 59 \\
\hline & RTC2 & - & 60.0 & 120 & 265 & 2.6 & 0.57 & - & 0.00 & 2.0 & 21 & 72 & 113 & 41 & 41 & 41 & 41 & 59 & 59 \\
\hline & - & VTC1 & 60.0 & 120 & 265 & 2.6 & 0.57 & 135 & 0.33 & 2.0 & 21 & 110 & 113 & - & - & - & - & 71 & 71 \\
\hline & - & VTC3 & 60.0 & 120 & 265 & 2.6 & 0.57 & 148 & 0.34 & 2.0 & 21 & 122 & 113 & - & - & 108 & 108 & - & - \\
\hline \multirow{4}{*}{$\begin{array}{l}\text { Bousselham } \\
\text { and Chaallal } \\
2006\end{array}$} & SB-S1-0L & - & 25.0 & 152 & 350 & 3.0 & 2.47 & - & 0.00 & 3.2 & 183 & 263 & 249 & 223 & 223 & 223 & 223 & 175 & 175 \\
\hline & - & SB-S1-0.5L & 25.0 & 152 & 350 & 3.0 & 2.47 & 192 & 1.00 & 3.2 & 183 & 282 & 249 & 259 & 249 & 285 & 249 & 200 & 200 \\
\hline & - & SB-S1-1L & 25.0 & 152 & 350 & 3.0 & 2.47 & 342 & 1.00 & 3.2 & 183 & 255 & 249 & 267 & 249 & 293 & 249 & 217 & 217 \\
\hline & - & SB-S1-2L & 25.0 & 152 & 350 & 3.0 & 2.47 & 684 & 1.00 & 3.2 & 183 & 267 & 249 & 274 & 249 & 303 & 249 & 238 & 238 \\
\hline \multirow{4}{*}{$\begin{array}{l}\text { Deniaud and } \\
\text { Cheng } 2001\end{array}$} & T6-S4 & - & 44.1 & 140 & 530 & 2.9 & 0.53 & - & 0.00 & 2.5 & 24 & 188 & 226 & 88 & 88 & 88 & 88 & 123 & 123 \\
\hline & - & T6-S4-C90 & 44.1 & 140 & 530 & 2.9 & 0.53 & 361 & 0.50 & 2.5 & 24 & 273 & 226 & 126 & 126 & 268 & 226 & 162 & 162 \\
\hline & T6-S2 & - & 44.1 & 140 & 530 & 2.9 & 1.06 & - & 0.00 & 2.5 & 49 & 357 & 316 & 177 & 177 & 177 & 177 & 162 & 162 \\
\hline & - & T6-S2-C90 & 44.1 & 140 & 530 & 2.9 & 1.06 & 361 & 0.50 & 2.5 & 49 & 310 & 316 & 214 & 214 & 356 & 316 & 201 & 201 \\
\hline
\end{tabular}

${ }_{1}^{1}$ Conversions from reported $f_{c u}$ use: $f_{c}=0.8 f_{c u}$. Conversion from reported psi values use: $\mathrm{MPa}=0.006895$ psi. Where the value of $f_{\mathrm{c}}$ for each individual beam is reported by the original

investigators, these values are used. Otherwise, mean values of $f_{c}$ reported by the original investigators for that series are used. 


\section{Results and discussion}

Figure 2(a) shows the peak normalised nominal shear stress for each test, plotted against the transverse steel reinforcement provision. The behaviour anticipated by the plastic web-crushing model is shown as a solid black curve. While there is some scatter, it can be seen that the experimental results are compatible with the pattern of behaviour anticipated by the plastic webcrushing model. In particular, the agreement at levels of transverse steel reinforcement $\psi$ less than $0.05 \mathrm{v}$, where crack-sliding failure might be expected to govern, is much improved for the retrofit beams.

(a)

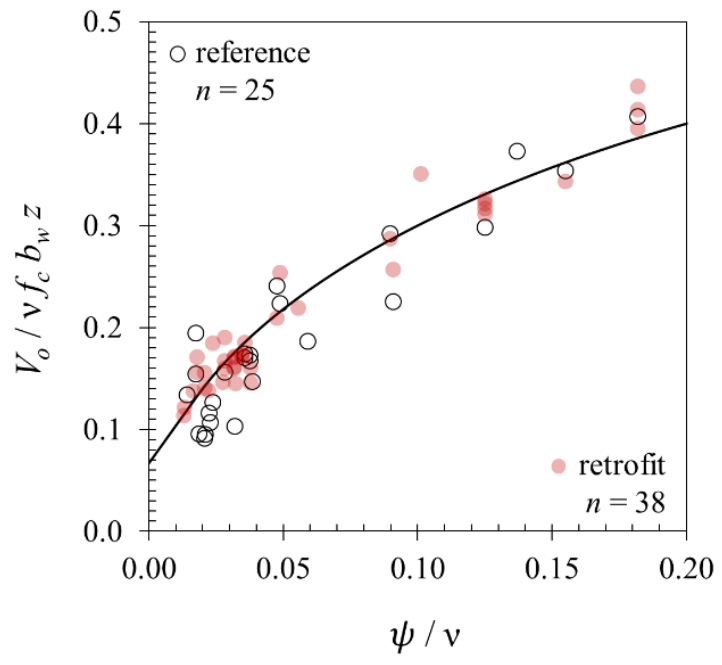

(b)

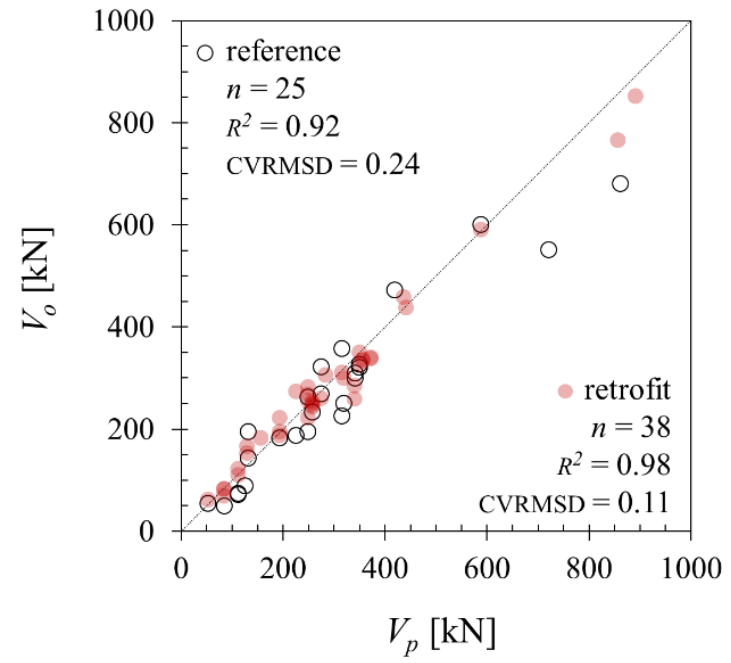

Figure 2: (a) Normalised shear stress attained versus normalised transverse steel reinforcement provision compared with the plastic web-crushing prediction denoted by the solid black curve; and (b) observed versus predicted shear capacity, for the reference beam tests and the retrofit beam tests.

Figure 2(b) compares the observed shear capacity $V_{0}$ for each beam with that predicted by the plastic model $V_{p}$. Very good agreement between the observed and predicted results is apparent for the retrofit beams. The coefficient of determination $R^{2}$ for the retrofit beams is 0.98 , indicating that a very high degree of the variation in the observed shear capacities of the retrofit beams is explainable by variation in the predicted shear capacities. The coefficient of determination for the reference beams is 0.92 , a strong correlation but lower than that for the retrofit beams. This is remarkable given that the retrofit CFRP has not been included in the plastic web-crushing model. While meaningful as an indicator of the degree of explained variation, $R^{2}$ is not a test of model goodness-of-fit for observed versus predicted values. Model goodness-of-fit requires the evaluation of the deviation of the observation-prediction value pairs from the 1:1 line rather than the regression line. For this reason, the coefficient of variation of the root mean square deviation (CVRMSD) is evaluated: 


$$
\text { CVRMSD }=\frac{\sqrt{\frac{1}{n} \sum_{i=1}^{n}(y-y)^{2}}}{y}
$$

where $n$ is the number of observation-prediction value pairs, $\hat{y}$ is the predicted value, $y$ is the observed value and $\bar{y}$ is the mean of the observed values. The squared $(\hat{y}-y)^{2}$ term of the CVRMSD penalises predictions that lie further from the 1:1 line but is neutral with respect to the conservatism or non-conservatism of predictions.

The plastic web-crushing model gives a lower CVRMSD of 0.11 for the retrofit beams than the value of 0.24 found for the reference beams. This means that the plastic web-crushing model is a better fit for retrofit beam behaviour than reference beam behaviour, despite the fact that the retrofit properties are not accounted for in the model. This suggests that the retrofit has a significant influence on beam behaviour, but that this influence is largely independent of the properties and arrangement of the CFRP, within the range represented by the tested retrofit beams. One physical interpretation of this might be that, above some minimum level, the retrofit provides sufficient restraint against diagonal crack dilation that web-crushing of the reinforced concrete is the governing failure mechanism, rather than sliding along a reduced strength yield line associated with a dilated diagonal crack. If the anchorage of the externally bonded CFRP is not adequate to ensure ductile behaviour from the retrofit system after web-crushing is initiated, then additional plastic capacity could not be expected from the presence of the CFRP.

Although the approach is theoretically upper-bound, the web-crushing analysis does not account for considerations such as the additional resistance that may be provided by the concrete flange, or the dowel action associated with the relatively high ratios of longitudinal reinforcement. In addition, the analysis makes use of a general concrete effectiveness factor not specifically calibrated for this arrangement. This means that the result that some experimental values of resistance exceed the web-crushing capacity is not particularly remarkable.

The apparent effect of the retrofit on beam capacity is illustrated in Figure 3 as a vector to each retrofit beam from its reference counterpart. Figure 3(a) relates the normalised shear stress attained to the normalised restraint stress due to the transverse steel reinforcement. Figure 3(b) compares the observed shear capacity to that predicted by the web-crushing model. In most cases where there is an apparent reduction in the reported capacity of the retrofit beam relative to that of the reference beam, the reference beam achieved a capacity close to or greater than the predicted web crushing capacity. It is also noticeable that in most cases where a reference beam achieved a reported shear capacity less than the predicted web-crushing capacity, the retrofit beam achieved an apparent enhancement. This suggests that - given some degree of variability in the underlying reinforced concrete T-beams - at least part of variation in the apparent reduction or enhancement in capacity that is usually ascribed to the retrofit may in fact be attributable to a form of 'regressionto-the-mean' in the observations. 
(a)

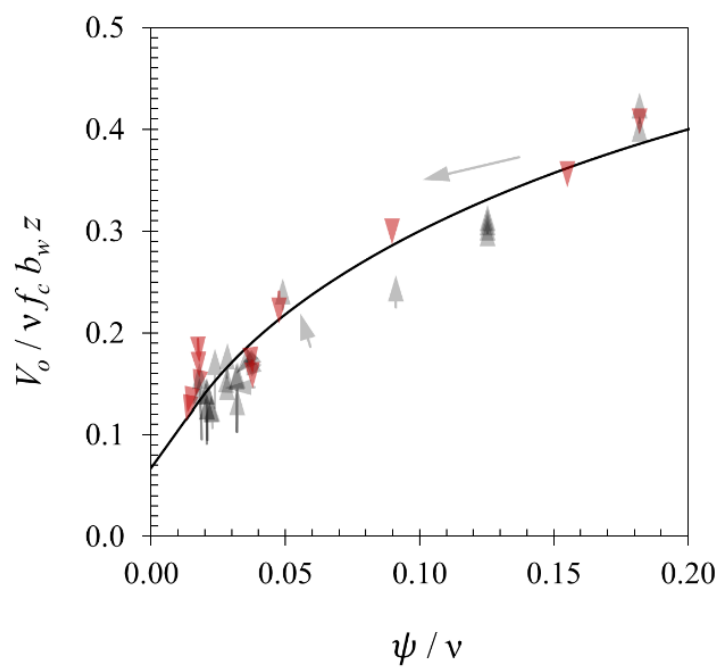

(b)

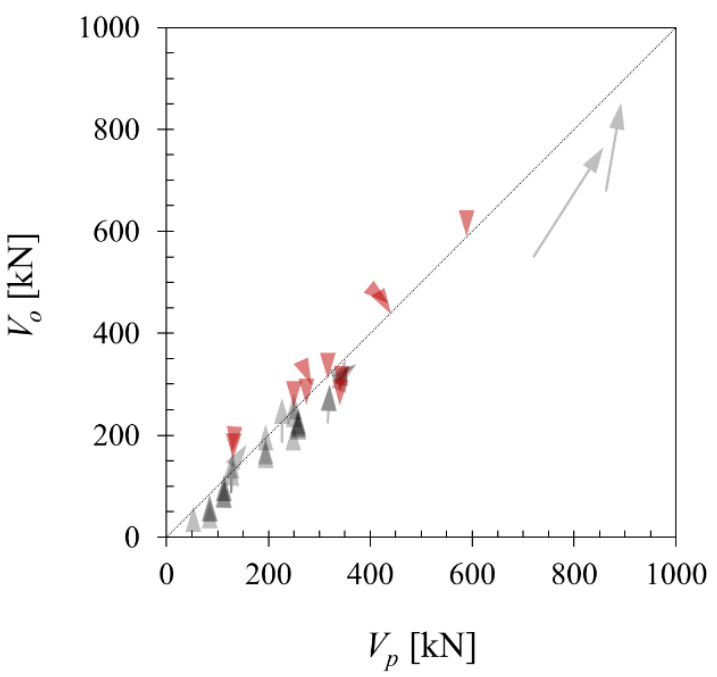

Figure 3: Vectors indicate the apparent influence of the retrofit on (a) normalised shear stress; and (b) shear capacity for each retrofit beam. Results for retrofit beams that achieved lesser capacities than their reference counterpart are highlighted.

It is informative to contrast these results with that of Dirar et al. (2012) beam U295/LP1/4.5, which was subject to pre-cracking up to $70 \%$ of estimated ultimate capacity followed by retrofit with 40\% ultimate load maintained and hence excluded from the dataset in accordance with criterion 6. In contrast with the initially unloaded beams used in this study, U295/LP1/4.5 displayed a significant increase in shear capacity relative to the reference beam U295/LP0/4.5 despite the reference beam having exceeded the predicted web crushing capacity. While it is important not to over-interpret a single test result, this may suggest that retrofit applied to a web with pre-existing dilated shear cracks may lead to different behaviour than retrofit applied to an initially unstrained and intact web. This may be the result of a number of factors including: the initiation of a (beneficially) shallower critical diagonal crack inclination prior to retrofit; the presence of an un-bonded gauge length of retrofit over the pre-dilated crack; the avoidance of a sudden redistribution of load to the retrofit as may occur during cracking of an initially intact web; the requirement that the retrofit system accommodate only the incremental strain beyond that associated with the load at installation (i.e., from $40 \%$ of estimated capacity) rather than the full loading cycle.

The lack of repeated in-series tests on reference beams makes it difficult to determine the degree of variability attributable to the underlying beams in the studies considered. In the absence of sufficient in-series replicates, it becomes necessary to consider the spread of cross-series results. Conceptually this is a large step and requires the assumption that the cross-series variability is similar to the in-series variability. Conventionally, a reference beam test and a retrofit beam test are considered as a fictitious pair, i.e. as a single notional beam before and after a retrofit intervention. In the following analysis the sets of reference and retrofit beam are instead 
considered as representative samples of two virtual populations: a population of un-retrofit beams and a population of retrofit beams. In order to control for the varying test parameters, the observed results $V_{o}$ for the reference and retrofit beams are normalised by the expected web-crushing capacity $V_{p}$. Figure 4a compares the distributions of the ratio of $V_{0} / V_{p}$ for the reference and the retrofit beam populations. The data are assumed independent and normally distributed with the same mean value $\bar{x}$ and standard deviation $\sigma$ as the samples. The real distributions may be slightly skewed as the left-hand tail is bounded by zero. However, since for both the reference and the retrofit beams; the sample means and medians are similar; and $\sigma<<\bar{x}$ with the left hand tails not approaching zero; the assumption of normally distributed results is likely to be a reasonable approximation.
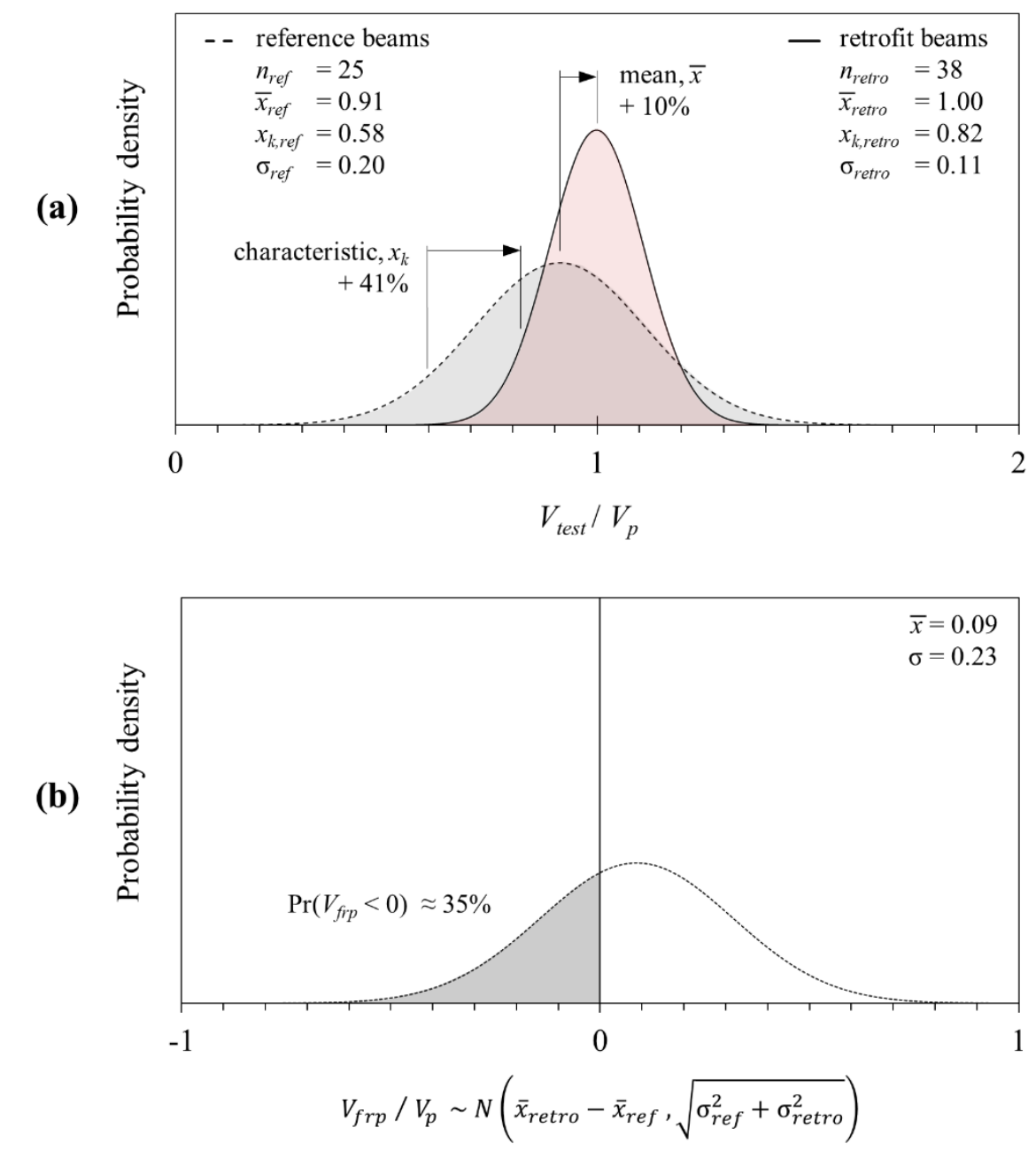

Figure 4: (a) Distribution of normalised reference and retrofit beam capacities; and (b) variation in $V_{\text {frp }}$ as difference of the distributions shown in (a).

The difference between $\bar{x}_{\text {retro }}$ and $\bar{x}_{\text {ref }}$ suggests an expected value of $10 \%$ for the 'strengthening' effect attributable to the presence of the retrofit. Because it is necessary in design to consider the adverse tail of the strength distribution (the left hand tail in Figure 4), the reduced variability 
associated with the provision of the retrofit indicates even greater potential for enhancement, with the lower $5^{\text {th }}$-percentile characteristic strength $x_{k}$ increasing by $41 \%$ for the set of beams considered here. Figure $4 \mathrm{~b}$ plots the difference between the distributions for the retrofit and reference beams shown in Figure 4a. Figure $4 \mathrm{~b}$ can thus be thought of as modelling $V_{f p p}$ as a stochastic variable normalised by $V_{p}$ where:

$$
V_{\text {frp }} / V_{p} \sim N\left(\bar{x}_{\text {retro }}-\bar{x}_{\text {ref }}, \sqrt{\sigma_{\text {ref }}^{2}+\sigma_{\text {retro }}^{2}}\right)
$$

Modelling $V_{f p}$ in this way suggests that the probability of a test finding a negative $V_{f p}$, i.e. a reference beam exceeding the capacity of its retrofit counterpart, is approximately $35 \%$. This is broadly compatible with the observation that $32 \%$ of retrofit beams identified in this study achieved a lesser capacity than a retrofit counterpart, suggesting that the assumptions made in this analysis are not unreasonable.

Figure 4 therefore provides some useful insight into why an apparent increase in capacity is most commonly observed; why an apparent reduction in capacity is sometimes observed; and why there is very poor predictability of the experimentally determined $V_{f p p}$. If the single control beam used in an experimental series happens, for example, to develop an adverse critical crack pattern and fail considerably below its web-crushing capacity; then retrofit counterparts, which consistently reach a value close to their web-crushing capacity, would lead the retrofit to be reported as providing considerable enhancement. If the control beam for the series had developed a favourable critical crack pattern and reached its web-crushing capacity; then retrofit counterparts, which also reach a value close to their web-crushing capacity might lead to a report of little, or even negative, enhancement. While experimental observations suggest that the web-crushing capacity may also be reduced in real terms by the loss of web concrete section associated with cover separation in the CFRP strengthened beams or variations in the inclination of critical diagonal cracks (Foster et al 2017a, Oller et al 2019), Figure 4 indicates that the underlying variabilities make it difficult to draw strong conclusions in this regard. Notwithstanding the paucity of the data and the somewhat broad assumptions this necessitates, the very substantial overlap between the distributions suggests that considerable caution is required in interpreting experimental values of $V_{f i p}$ based on few reference counterparts.

The good correlation of the web-crushing prediction to the experimental capacity of the retrofit beams, independent of consideration of the CFRP, suggests a new perspective on the role of the externally bonded CFRP retrofit. Instead of considering the retrofit as providing a component of force to be superimposed, it might be preferable to consider the CFRP as helping to ensure the integrity of the underlying beam, thereby ensuring that the beam does not fail by some mechanism that precedes web-crushing. An example of such a pre web-crushing failure mode might be that of the sliding failure along a critical diagonal crack, which is associated with values of $\psi / \nu \lesssim 0.05$. In the retrofit case, the propagation of a critical diagonal crack or cracks might be delayed by the local restraining or bridging effect of the CFRP crossing the crack. This would accord with the 
delay in the onset of softening associated with the formation of a critical diagonal crack reported by Foster et al. (2017a). This effect has also been observed in modified push-off tests designed to elicit combinations of shear and tension across an interface in concrete strengthened with CFRP (Foster et al. 2016).
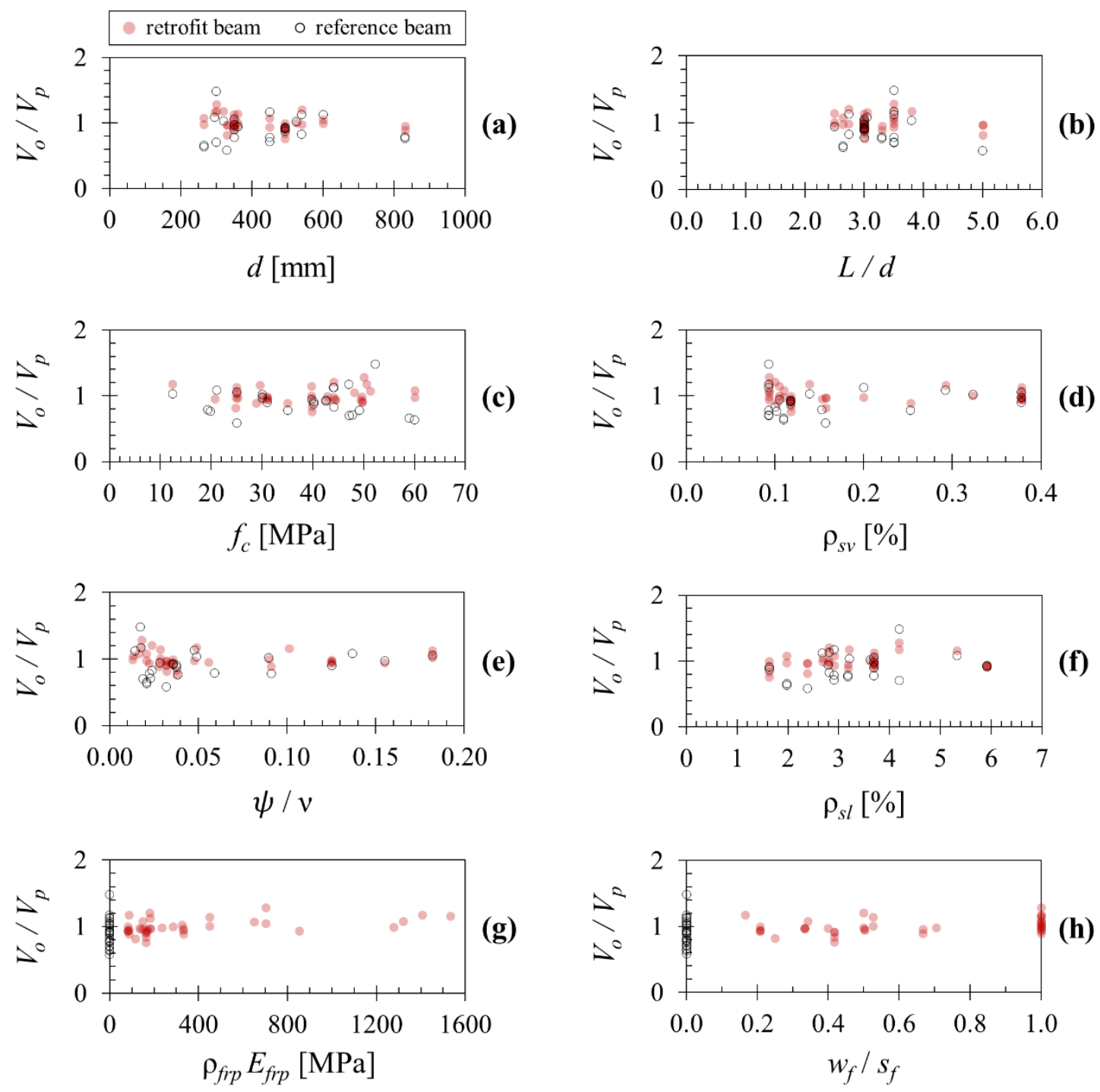

Figure 5: Influence of various parameters on the accuracy of the predictions of the plastic webcrushing model.

Figure 5 presents plots of the accuracy of the plastic web-crushing model predictions for retrofit and reference beams, against a number of parameters that might be expected to influence retrofit T-beam behaviour. Figure 5(a-e) consider parameters $d, L, f_{c}, \varrho_{s v}, \psi, v$ that are included in the model; and Figure 5(f-h) consider parameters $\varrho_{s}, \varrho_{f p}, E_{f i p}, w_{f}$ and $s_{f}$, that are not included in the model. Figure 5(a-e) indicate little or no correlation between prediction accuracy and: depth $d$; shear span to depth ratios $L / d$; concrete strength $f_{i}$; transverse reinforcement percentage $\varrho_{s v}$; or the transverse steel reinforcement parameter $\psi / \nu$. This suggests that the influence of these parameters is 
appropriately captured by the model within the range considered. There is little indication of reduced accuracy of the plastic web-crushing model for the retrofit in comparison to the reference beams at $\psi / \nu \lesssim 0.05$ suggesting that the influence of crack-sliding associated with low levels of transverse steel reinforcement is substantially reduced by the retrofit. Figure $5(f)$ shows little or no correlation between prediction accuracy and longitudinal reinforcement ratio $\varrho_{s}$, a parameter not included in the model. This is somewhat surprising as an increasing dowel effect with increasing $\varrho_{s l}$ might be anticipated. However, the relatively high values of $\varrho_{s l}$ found in the experimental dataset mean that it is difficult to draw conclusions about the influence of longitudinal reinforcement for $\varrho_{s l} \lesssim 2.0 \%$. Figure $5(\mathrm{~g})$ and $(\mathrm{h})$ indicate little or no correlation between the accuracy of the model and either $\varrho_{f i p} E_{f i p}$, which can be taken as a proxy for the degree of CFRP provision, or the CFRP spacing $w_{f} / s_{f}$. This suggests that, beyond some minimum provision of CFRP needed to ensure the integrity of the web concrete (e.g. prevent crack-sliding), there may be little or no incremental enhancement to be gained from provision of further CFRP. While further investigation would be required to determine the minimum CFRP provision required to elicit a strengthening effect of the type postulated here, Figure 5(g) suggests that this level may be below that of any of the test beams considered in this study.

UK guidance TR55 (Concrete Society 2012) builds upon the European design code EC2 (BSI 2004) lower-bound variable-angle truss model for calculating shear resistance in the underlying reinforced concrete beam by superposing an additional fixed-angle truss incorporating the FRP. Italian guidance CNR DT 200 R1/2013 (CNR 2014) also builds upon EC2 but provides for a second variable-angle truss incorporating the FRP. US design code ACI 440.2R-17 (ACI 2017) builds upon the ACI 318-14 (ACI 2014) concrete plus fixed-angle truss model by superposing a second fixed-angle truss tied by the FRP. All three codes require that the capacity of the notional concrete struts of the truss is not exceeded. Figure 6 and Table 3 compare the observed versus predicted values for the retrofit beams according to the plastic web-crushing model, and to the TR55, CNR DT 200 and ACI 440.2 truss models. Mean material properties are used and explicit partial safety factors are set to a value of one. TR 55, CNR DT 200 and ACI 440.2 each place different limitations on the allowable spacing of discrete strips meaning that the number of beams $n$ varies depending upon the code considered. The significantly lower CVRMSD of the predictions of the plastic web-crushing analysis suggests that web-crushing is a more consistent predictor of the behaviour of the retrofit T-beams than either TR 55, CNR DT 200 or ACI 440.2. The higher $\mathrm{R}^{2}$ of the predictions of the plastic web-crushing analysis further suggests that web crushing better explains variation in the observed values than the models underpinning TR 55, CNR DT 200 and ACI 440.2. The parsimony of the web-crushing model and its accuracy in predicting retrofit beam capacity suggests that upper-bound plastic analyses of this type offer a promising direction for the design of better retrofit interventions. 

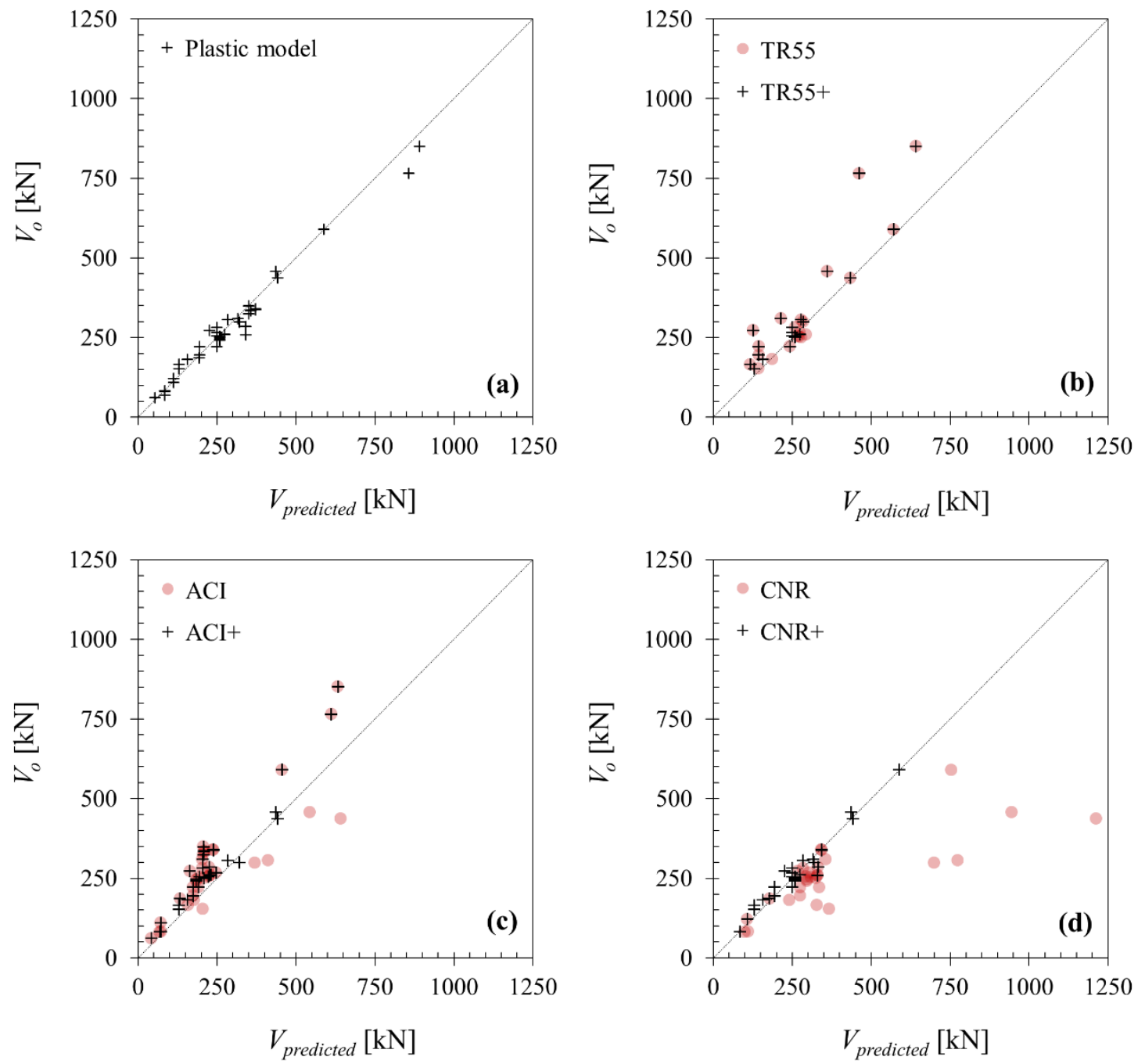

Figure 6: Observed versus predicted values for (a) plastic web-crushing model; (b) TR55; (c) ACI 440.2; and (d) CNR DT 200, with and without the additional limitation proposed

Table 3: Ratios of observed to predicted shear capacity for various design guidance, with and without the additional limitation proposed.

\begin{tabular}{lccccccc} 
& $V_{o} /$ & $V_{o} /$ & $V_{o} /$ & $V_{o} /$ & $V_{o} /$ & $V_{o} /$ & $V_{o} /$ \\
& $V_{P}$ & $V_{\text {TR55 }}$ & $V_{C N R}$ & $V_{A C I}$ & $V_{\text {TR55+ }}$ & $V_{C N R+}$ & $V_{A C I+}$ \\
\hline $\boldsymbol{n}$ & 38 & 21 & 29 & 36 & 21 & 29 & 36 \\
$\overline{\boldsymbol{x}}$ & 1.00 & 1.19 & 0.77 & 1.25 & 1.23 & 1.02 & 1.30 \\
CVRMSD & 0.11 & 0.29 & 0.83 & 0.31 & 0.29 & 0.09 & 0.28 \\
$\boldsymbol{R}^{2}$ & 0.98 & 0.82 & 0.60 & 0.76 & 0.84 & 0.95 & 0.92 \\
\hline
\end{tabular}




\section{DESIGN PROPOSAL}

TR55 (Concrete Society 2012) and ACI440.2 (ACI 2017) place limitations on the maximum enhancement allowable using externally bonded FRP retrofit systems in general. These limitations relate broadly to the understanding that it is prudent to design such that a structure's un-retrofit capacity is not less than the service loads on the structure. This is intended to prevent collapse of a structure due to loss of the FRP retrofit due to unforeseen events such as accident, vandalism or fire. CNR DT 200 (CNR 2014) places a similar general limitation on enhancement at $50 \%$ of the capacity of the underlying member. While such limitations have the beneficial effect of curbing some potentially unsafe retrofit design by placing a ceiling on the degree of enhancement available, this appears to be incidental and results from prudence in risk management rather than the adequacy of the mechanical models adopted.

The plastic web-crushing capacity has been shown here to provide a good prediction of retrofit beam behaviour. It can also be seen that in most cases where an apparent enhancement in capacity is observed experimentally, the enhanced capacity achieved is not significantly greater than the plastic web-crushing capacity of the underlying beam. This suggests that, for the purposes of design, it may be prudent to provide a further limitation on enhancement. This would be to limit the enhanced capacity of a beam retrofit with unanchored externally bonded CFRP to no more than that of the web-crushing capacity of the underlying beam. In other words, the capacity of the retrofit beam should not be taken as greater than that indicated by a plastic web-crushing analysis as being the lowest upper bound capacity for the un-retrofit reinforced concrete section. This is suggested as a general limitation appropriate to the evaluation of capacity subject to the application of appropriate partial safety factors.

The predicted shear capacity following TR55, CNR DT 200 and ACI440.2 with the additional limit that the prediction should not exceed $V_{p}$ as described above is denoted here as $V_{\text {TR55+, }} V_{C N R+}$ and $V_{A C I+}$. Figure 6 and Table 3 indicate that, for the beams considered, the proposed limitation would positively affect the accuracy of CNR DT 200 and ACI 440.2. The limitation would have little effect on the accuracy of TR55, which is already somewhat conservative. Given that there is also some evidence that the separation of the CFRP may reduce the effective web cross section it may also be prudent to consider reducing the nominal web area to exclude the compromised cover concrete for the purposes of design.

\section{SUMMARY AND CONCLUSIONS}

This paper presents a new perspective on the effect of unanchored externally bonded CFRP retrofit on the shear capacity of reinforced concrete T-beams. This perspective explains the historically poor prediction of the FRP component of resistance $V_{f p}$ and posits a new role for the upper bound theorem of plasticity in enabling better assessment and design of reinforced concrete structures retrofit with CFRP. 
The following conclusions are drawn from this investigation:

1. Of the 38 realistically sized T-beams retrofit with unanchored externally bonded CFRP that were identified by this study, 12 attained a lesser shear capacity than one or more of their respective reference counterparts.

2. Variability in the capacity of reinforced concrete reference beams has a considerable and largely unrecognised influence on the apparent accuracy of predictions of the FRP component of resistance $V_{f p p}$. This means that the FRP component of resistance $V_{f t p}$ cannot be simply determined as the difference between the shear capacity of a singular retrofit specimen and a reference counterpart.

3. A plastic web-crushing model applied here without explicit consideration of the CFRP retrofit provides a consistent prediction of retrofit beam capacity, suggesting that the retrofit acts to preserve the integrity of the concrete web, rather than providing a separate component of force $V_{f p p}$. This action appears to persist only up until approximately the plastic web-crushing limit for the un-retrofit beam is reached.

4. The distribution of ratios of tested values to those predicted by the web-crushing model suggests that externally bonded CFRP retrofit provides a 10\% mean gain in shear capacity and a $41 \%$ gain in $5^{\text {th }}$ percentile characteristic shear capacity for the set of beams considered in this study.

5. Considering $V_{f p p}$ as a normally-distributed stochastic variable having the same distribution as the difference between the normalised capacities of the retrofit and reference beams can explain the variability in the experimentally determined CFRP contribution reported in the literature, including the incidence of apparent 'negative' contributions.

6. The web-crushing model provides a better prediction of retrofit shear capacity than existing guidance TR55, CNR DT 200 and ACI440.2 for the beams considered in this study. This suggests that the web-crushing analysis provides a promising basis for better assessment and design of reinforced concrete slab-on-beam structures retrofit with externally bonded CFRP.

7. Loss of web cover concrete section due to separation of the CFRP and changes to the inclination of critical diagonal cracks may provide further explanation of these negative values; however, the degree of variability observed makes it difficult to draw strong conclusions in this regard.

8. A proposed new limitation - that the capacity of the retrofit beam should not be taken as greater than that indicated by a web-crushing analysis for the underlying reinforced concrete section - is shown to improve the accuracy of some widely used design guidance. Incorporating this limitation into existing guidance can thus immediately reduce the likelihood of unsafe design of externally bonded CFRP retrofit interventions in practice. 


\section{DATA AVAILABILITY STATEMENT}

All data, models, and code generated or used during the study appear in the submitted article. The analysis presented in this publication is underpinned by published experimental data whose original sources are indicated in the references.

\section{ACKNOWLEDGEMENTS}

The authors gratefully acknowledge the support of the UK Engineering and Physical Sciences Research Council (EPSRC) through grant EP/I018972/1.

\section{REFERENCES}

ACI (American Concrete Institute) (2014). "Building Code Requirements for Structural Concrete and Commentary", ACI 318-14, American Concrete Institute: Farmington Hills

ACI (American Concrete Institute) (2017) "Guide for the design and construction of externally bonded FRP systems for strengthening concrete structures." ACI 440.2R-17, American Concrete Institute: Farmington Hills

Altin, S., O. Anil, Y. Kopraman, C. Mertoglu, and M. E. Kara (2010). "Improving shear capacity and ductility of shear-deficient RC beams using CFRP strips." J. Reinf. Plast. Compos. 29 (19): 2975-2991. https://doi.org/10.1177/0731684410363182.

AS (Australia Standards) (2008). Design handbook for RC structures retrofitted with FRP and metal plates: Beams and slabs. HB 305. Sydney: AS

Bakis, C. E., Bank, L. C., Brown, V. L., Cosenza, E, Davalos, J. F., Lesko, J. J., Machida, A., Rizkalla, S. H., \& Triantafillou, T. C. (2002). "Fiber-reinforced polymer composites for construction - State-of-the-art review”, J. Compos. Constr., 6, 73-87

Belarbi, A., Bae, S-W. \& Brancaccio, A. (2012) "Behavior of full-Scale RC T-beams strengthened in shear with externally bonded FRP sheets", Constr. Build. Mater., 32, 27-40

Bentz, E.C., Vecchio, F.J. \& Collins, M.P. (2006) "Simplified Modified Compression Field Theory for Calculating Shear Strength of Reinforced Concrete Elements”, ACI Struct. J., 103(4), 604624

Benzeguir, Z.E.A., El-Saikaly, G. and Chaallal, O. (2018) "Influence of size on the behaviour of RC T-beams strengthened in shear with externally bonded CFRP”, $9^{\text {th }}$ International Conference on Fibre-Reinforced Polymer Composites (CICE 2018), Paris, 17-19 July 2018 
Bousselham, A. \& Chaallal, O. (2006) "Behavior of reinforced concrete T-Beams strengthened in shear with carbon fiber-reinforced polymer-an experimental study", ACI Struct. J., 103(3), 339-347

BSI (2004), EN 1992-1-1:2004 'Design of Concrete Structures. General Rules and Rules for Buildings', BSI: London

Chen, C. and Cheng, L. (2019) "Single Crack-Based Model for FRP Shear-Strengthened RC Beams, J. Compos. Constr., 23(4), 04019030

Chen, G.M., Teng, J.G. and Chen, J.F. (2013) "Shear Strength Model for FRP-Strengthened RC Beams with Adverse FRP-Steel Interaction”, J. Compos. Constr., 17(1), 50-66

Chen, G.M., Li, S.W., Fernando, D., Liu, P.C. and Chen, J.F. (2017) "Full-range FRP failure behaviour in RC beams shear-strengthened with FRP wraps", Int. J. Solids Struct., 125, 1-21

CNR (Consiglio Nazionale delle Ricerche) (2014) "Guide for the Design and Construction of Externally Bonded FRP Systems for Strengthening Existing Structures , CNR-DT 200 R1/2013, Consiglio Nazionale delle Ricerche: Rome [English language version]

Concrete Society (2012) "Design guidance for strengthening concrete structures using fibre composite materials." Technical Rep. No. 55, Concrete Society: Camberley

De Lorenzis, L. and Nanni, A. (2001) "Shear Strengthening of Reinforced Concrete Beams with Near-Surface Mounted Fiber-Reinforced Polymer Rods", ACI Struct. J., 98(1), 60-68

Deniaud, C., and Cheng, J. J.R. (2001) "Shear behavior of reinforced concrete T-beams with externally bonded fiber-reinforced polymer sheets”, ACI Struct. J., 98(3), 386-394

Denton, S. R., Shave, J. D., and Porter, A. D. (2004). "Shear strengthening of reinforced concrete structures using FRP composite." Advanced polymer composites for structural applications in construction, L. C. Hollaway, M. K. Chryssanthopoulos, and S. S. J. Moy, eds., Woodhead, Cambridge, U.K., 134-143.

Dirar, S., Lees, J., and Morley, C. (2012) "Precracked reinforced concrete T-beams repaired in shear with bonded carbon fiber-reinforced polymer sheets", ACI Struct. J., 109(2), 215-224

fib (Fédération internationale du béton) (2001) "Externally bonded FRP reinforcement for RC structures-Technical report on the design and use of externally bonded fibre reinforced polymer reinforcement for reinforced concrete structures", Bulletin 14, Fédération internationale du béton: Lausanne 
Foster, R.M., Morley, C.T. and Lees, J.M. (2016) "Modified Push-Off Testing of an Inclined Shear Plane in Reinforced Concrete Strengthened with CFRP Fabric", J. Compos. Constr., 20(3), 04015061

Foster, R.M., Brindley, M., Lees, J.M., Ibell, T.J., Morley, C.T., Darby, A.P., Evernden, M.C., (2017a) "Experimental investigation of reinforced concrete T-beams strengthened in shear with externally bonded CFRP sheets", J. Compos. Constr., 21(2), 04016086

Foster, R.M., Haria, S., Morley, C.T. and Lees, J.M. (2017b) "Shear Capacity of Reinforced Concrete Subjected to Tension: Experimental Results and Analysis”, J. Struct. Eng., 143(9), 04017085

Hoult, N.A. \& Lees, J.M. (2009) "Efficient CFRP strap configurations for the shear strengthening of reinforced concrete T-beams", J. Compos. Constr., 13(1), 45-52

Ibell, T.J., Morley, C.T. and Middleton, C.R. (1997) 'A Plasticity Approach to the Assessment of Shear in Concrete Beam and Slab Bridges', The Structural Engineer, 75(19), pp. 331-338

Jensen, B.C. (1977) 'Some Applications of Plastic Analysis to Plain and Reinforced Concrete', Institute of Building Design Report No. 123, Technical University of Denmark: Copenhagen

Ji, C., W. Li, C. Hu, and F. Xing (2017) "Data analysis on fiber-reinforced polymer shear contribution of reinforced concrete beam shear strengthened with U-jacketing fiberreinforced polymer composites." J. Reinf. Plast. Compos. 36 (2), 98-120.

Khalifa, A., Gold, W., Nanni, A., and Abel-Aziz, M. (1998). "Contribution of externally bonded FRP to the shear capacity of RC flexural members." J. Compos. Constr., 2(4), 195-202.

Lima, J. L., and Barros, A. B. (2011) "Reliability analysis of shear strengthening externally bonded FRP models." Struct. Build., 64(1), 43-56

Mofidi, A., Challal, O., Benmokrane, B. and Neale, K. (2012) "Performance of End-Anchorage Systems for RC Beams Strengthened in Shear with Epoxy-Bonded FRP”, J. Comp. Constr., 16(3), 322-331

Mofidi, A. \& Chaallal, O. (2014a) "Effect of steel stirrups on shear resistance gain due to externally bonded fiber-reinforced polymer strips and sheets", ACI Struct. J., 111(2), 353-361

Mofidi, A. \& Chaallal, O. (2014b) "Tests and design provisions for reinforced-concrete beams strengthened in shear using FRP sheets and strips", International Journal of Concrete Structures and Materials, 8(2), 117-128 
Mofidi, A., Chaallal, O., Cheng, L. and Shao. Y. (2016) "Investigation of Near Surface-Mounted Method for Shear Rehabilitation of Reinforced Concrete Beams Using Fiber ReinforcedPolymer Composites", J. Compos. Constr., 20(2), 04015048

Nielsen, M. P., Braestrup, M. W. \& Bach, F. (1978), 'Rational Analysis of Shear in Reinforced Concrete Beams', LABSE Proceedings -15/78, 1-16, http://dx.doi.org/10.5169/seals-33219

Nielsen, M.P. and Hoang, L.C. (2011) Limit Analysis and Concrete Plasticity (3rd Ed.), CRC Press: London

Oller, E., Pujol, M. and Mari, A. (2019) "Contribution of externally bonded FRP shear reinforcement to the shear strength of RC beams", Composites Part B, 164, 235-248

Ozden, S., H. M. Atalay, E. Akpinar, H. Erdogan, and Y.Z. Vulaş (2014) "Shear strengthening of reinforced concrete T-beams with fully or partially bonded fibre-reinforced polymer composites." Struct. Concr., 15, 229-239

Pellegrino, C., and C. Modena (2008) "An experimentally based analytical model for shear capacity of FRP strengthened reinforced concrete beams.” Mech. Compos. Mater., 44, 231-244.

Petrone, F., \& Monti, G. (2014) "FRP-RC Beam in Shear: Mechanical Model and Assessment Procedure for Pseudo-Ductile Behavior", Polymers, 6, 2051-2064

Qin, S., Dirar, S., Yang, J. and Chan, H.C. (2015) "CFRP Shear Strengthening of ReinforcedConcrete T-Beams with Corroded Shear Links", J. Compos. Constr., 19(5), 04014081

Triantafillou, T. C., and Antonopoulos, C. P. (2000). "Design of concrete flexural members strengthened in shear with FRP.” J. Compos. Constr., 4(4), 198-205.

Valerio, P., Ibell, T.J. and Darby, A.P. (2009) "Deep embedment of FRP for concrete shear strengthening", Structures and Buildings, 162(5), 311-321

Zhang, J-P. (1994) "Strength of Cracked Concrete, Part 1 - Shear Strength of Conventional Reinforced Concrete Beams, Deep Beams, Corbels, and Prestressed Reinforced Concrete Beams without Shear Reinforcement", Structural Research Lab Report No. R-311, Technical University of Denmark, Copenhagen

Zhang, J.-P. (1997) "Strength of cracked concrete. Part 2: Micromechanical modelling of shear failure in cement paste and in concrete", Structural Research Lab Rep. No. R-17, Technical University of Denmark, Copenhagen 